\title{
Supramolecular polymer formed by ditopic cyclodextrin and ditopic adamantane derivatives.
}

Alvaro Antelo, Mercedes Alvarez Alcalde, Aida Jover, Francisco Meijide, Luciano Galantini ${ }^{1}$ and José Vázquez Tato

Departamento de Química Física, Facultad de Ciencias, Universidad de Santiago de Compostela, Avda. Alfonso X El Sabio s/n, 27002 Lugo, Spain,

${ }^{1}$ Dipartimento di Chimica, Research center SOFT-INFM-CNR, Università di Roma "La Sapienza", P.le A. Moro 5, 00185 Roma, Italy.

\begin{abstract}
Novel host-guest supramolecular copolymers have been prepared from a $\beta$-cyclodextrin (binded to ethylenediamintetraacetic acid, EDTA) dimer and a ditopic guest with two adamantyl groups bound to pyromellitic acid. Molecular weight and molecular size were determined from static and dynamic light scattering measurements (SLS and DLS, respectively). The analysis of results suggests that the supramolecular polymer adopts a shruck structure with an average molecular weight value of $M_{\mathrm{n}}=$ $(1.51 \pm 0.02) \times 10^{4} \mathrm{~g} \cdot \mathrm{mol}^{-1}$ (degree of polymerization equal to 5$)$.
\end{abstract}

\section{Introduction}

Supramolecular polymers consist of arrays of low molecular weight molecules linked by noncovalent interactions. ${ }^{1}$ The most important feature is the inherent reversibility associated with intermolecular interactions. Therefore these polymers are in continuous equilibrium with their environment, and their properties, a priori, may be adjusted by external stimuli, providing new opportunities for designing tunable materials. $^{2}$

Ionic interactions, ${ }^{3}$ nucleobase pair interactions, ${ }^{4}$ interprotein heme heme pocket binding, ${ }^{5}$ metal coordination, hydrogen bonding, ${ }^{6,7}$ and host-guest interactions of crown ether/organic salt ${ }^{8}$ or cyclodextrin/hydrophobic molecule systems ${ }^{9-12}$ have been exploited for the polymerization. ${ }^{13}$ In particular, host-guest supramolecular polymers, some of which show very interesting potential applications, have been obtained by using the hosting properties of cyclodextrins. ${ }^{14-16}$ Polymers have been obtained either by mixing unimers carrying complementary units, i.e., host and guest sites, ${ }^{14,17}$ or 
complementary monomers having two interacting host or guest moieties. ${ }^{15}$ With suitable guests these molecules give rise to very stable inclusion complexes that, when employed in the polymerization, should guarantee high polymerization degrees. ${ }^{18}$ However, very often, small cyclic structures or chelate complexes seem to be formed which prevent the growth of large polymers. ${ }^{19,20}$

Adamantyl derivatives form inclusion complexes with cyclodextrins, the interaction being highly favorable. This preference is due to a good fit of the adamantyl group inside the $\beta$-cyclodextrin $(\beta C D)$ cavity. $^{21}$ For this reason, supramolecular copolymers have been recently prepared by mixing different $\beta$-cyclodextrin and adamantyl dimers (Figure 1). Preliminary results on these systems seem to show that the polymerization degree strongly depends on the polymer flexibility, which determines the formation of closed structures, and stops the growth to small cyclic oligomers. ${ }^{22}$ In the light of this interest, in this work, we reported preparation and characterization of a new supramolecular copolymer.

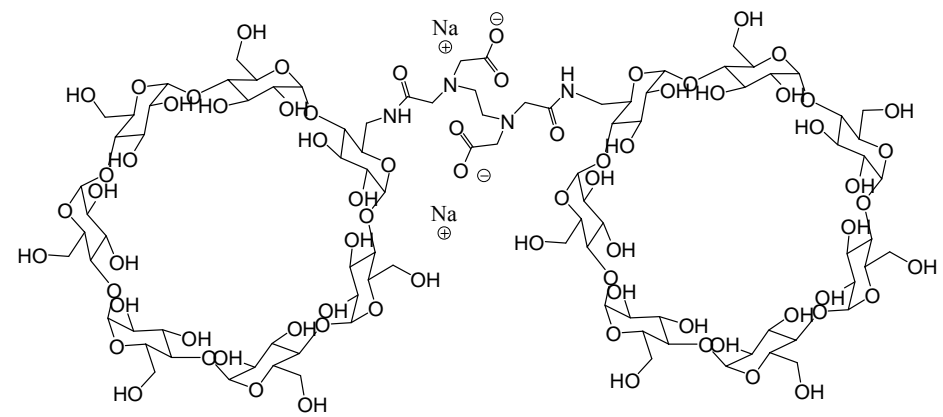

(a)

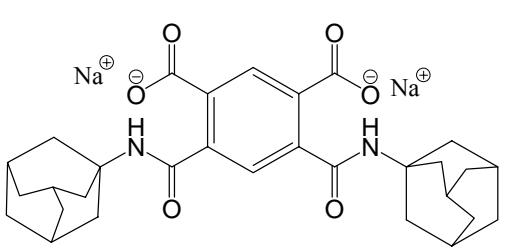

$m-\operatorname{Ad}_{2}(10 \%)$

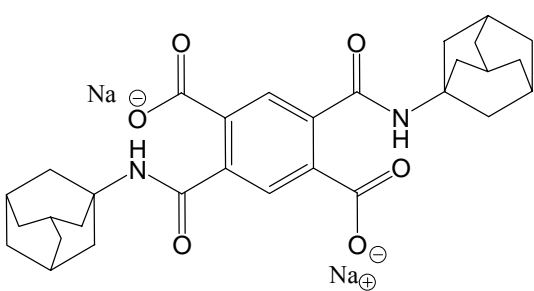

$\mathrm{p}-\mathrm{Ad}_{2}(90 \%)$

(b)

Figure 1.- Structures of the precursors of the supramolecular polymer. (a) $\beta$-CD dimer derivative $\left(\beta C D_{2}\right.$ EDTA). (b) Adamantyl dimer $\left(\mathrm{Ad}_{2}\right)$, isomer mixture used on polymer generation.

\section{Experimental section}

Synthesis of $\boldsymbol{\beta C} \boldsymbol{D}_{2} \boldsymbol{E D T A}$ : $6-\mathrm{NH}_{2}-\beta-\mathrm{CD}(1.2 \mathrm{~g}, 1.06 \mathrm{mmol})$ and EDTA dianhydride $(0.12 \mathrm{~g}, 0.47 \mathrm{mmol})$ were dissolved in dry DMF $(10 \mathrm{~mL})$. Then $0.3 \mathrm{~mL}$ of 
triethylamine were added and the mixture stirred at $50^{\circ} \mathrm{C}$ for one day under argon atmosphere. $\mathrm{H}_{2} \mathrm{O}(\sim 5 \mathrm{~mL})$ was then added and the resultant mixture stirred 1 hour at r.t. After evaporation, the residue was taken up in $\mathrm{H}_{2} \mathrm{O}(\sim 5 \mathrm{~mL})$ and purified is a Sephadex C-25 column with water as eluent. Yield $85 \% . \mathrm{R}_{\mathrm{f}}=0.17$ (Ethyl acetate: 2-propanol: water: ammonia / 2: 3: 4: 0.3). RMN. ${ }^{1} \mathrm{H}$ RMN ( $\left.\mathrm{D}_{2} \mathrm{O}, 500 \mathrm{MHz}, \delta / \mathrm{ppm}\right)$ : 5.13-5.04 (bs, 12H$\left.\mathrm{C}(1), 2 \mathrm{H}-\mathrm{C}\left(1^{\prime}\right)\right)$; 4.04-3.76 (m, 12H-C(3), 12H-C(5), 24H-C(6), 2H-C(3'), 2H-C(6'), 2H-C(5'), $4 \mathrm{CH}_{2} \mathrm{COO}, 4 \mathrm{CH}_{2} \mathrm{CON}$ ); 3.72-3.64 (m, 12H-C(2), 2H-C(2')); 3.63-3.50 (m, 12H-C(4), 2H-C(4'); 3.44 (t, J=9.2, 2H-C(6')); $3.22\left(\mathrm{~s}, \mathrm{CH}_{2} \mathrm{CH}_{2}\right) .{ }^{13} \mathrm{C} \mathrm{RMN} ;\left(\mathrm{D}_{2} \mathrm{O}, 500 \mathrm{MHz}, \delta / \mathrm{ppm}\right): 181.8$ (COO); 177.6 (CON); 104.6 (C(1), C(1')); 85.8 C(4'); 83.9 C(4); 75.9 C(2); 75.6 C(2’); $74.8 \mathrm{C}(3)$; 74.7 $\mathrm{C}\left(3^{\prime}\right) ; 74.6 \mathrm{C}(5)$ : $72.6 \mathrm{C}\left(5^{\prime}\right) ; 63.1 \mathrm{C}(6) ; 61.1\left(\mathrm{CH}_{2} \mathrm{COO}\right) ; 60.9\left(\mathrm{CH}_{2} \mathrm{CON}\right) ; 55.5\left(\mathrm{CH}_{2} \mathrm{CH}_{2}\right) ; 42.6$ $\mathrm{C}\left(6^{\prime}\right)$. MALDI-TOF: Calculated $=2524,21 \mathrm{~g} \cdot \mathrm{mol}^{-1}$; observed $=2544,82\left([\mathrm{M}+\mathrm{Na}]^{+}\right)$.

Synthesis of $\boldsymbol{A d}_{2}$ : 1-AdNH 2 . (2.3 g, $\left.15.2 \mathrm{mmol}\right)$ and Pyromellitic dianhydride $(1.5 \mathrm{~g}, 6.9 \mathrm{mmol})$ were dissolved in dry DMF $(25 \mathrm{~mL})$. Then $2 \mathrm{~mL}$ of triethylamine were added and the mixture stirred at r.t. for one day under argon atmosphere (at 10 minutes a precipitate was observed). $\mathrm{H}_{2} \mathrm{O}(\sim 5 \mathrm{~mL})$ was then added and the mixture stirred 1 hour at r.t. Finally, solid was filtered and washed with $2 \times 10 \mathrm{~mL}$ of methanol to remove non reacted pyromellitic and then washed with water at $\mathrm{pH}=2$ to remove $1-\mathrm{AdNH}_{2}$ and to ensure carboxylic acid generation. Para- and meta- isomers were obtained at 10/90 ratio (see Figure 2). Yield 85\%.

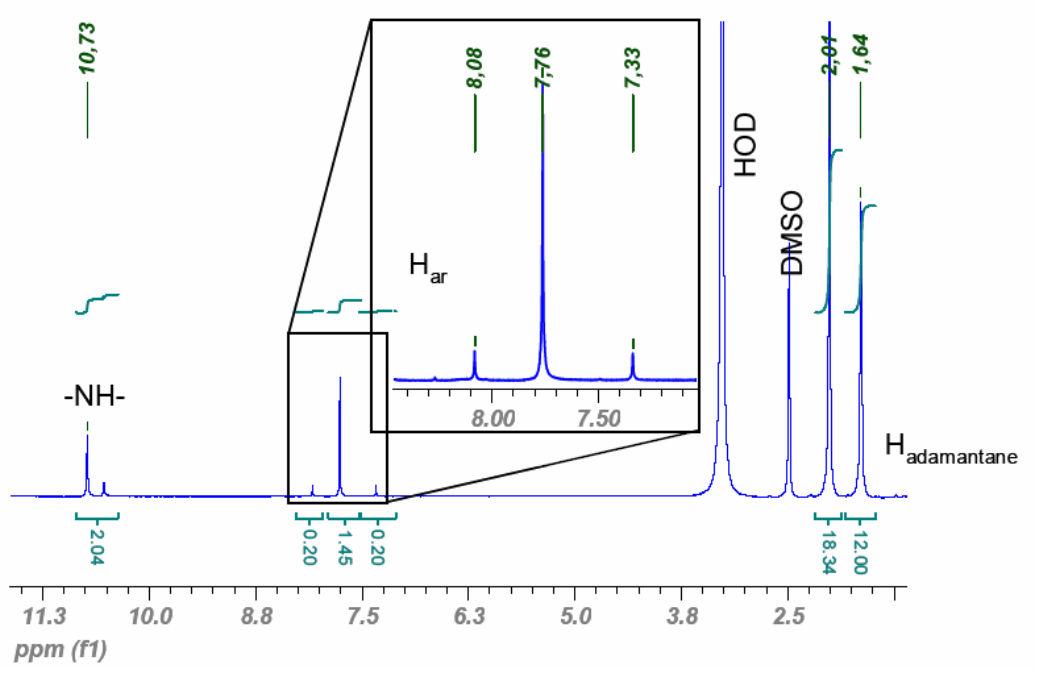

Figure 2.- ${ }^{1} \mathrm{H}$ spectrum of $A d_{2}$ in DMSO-d6. $300 \mathrm{MHz}$. 


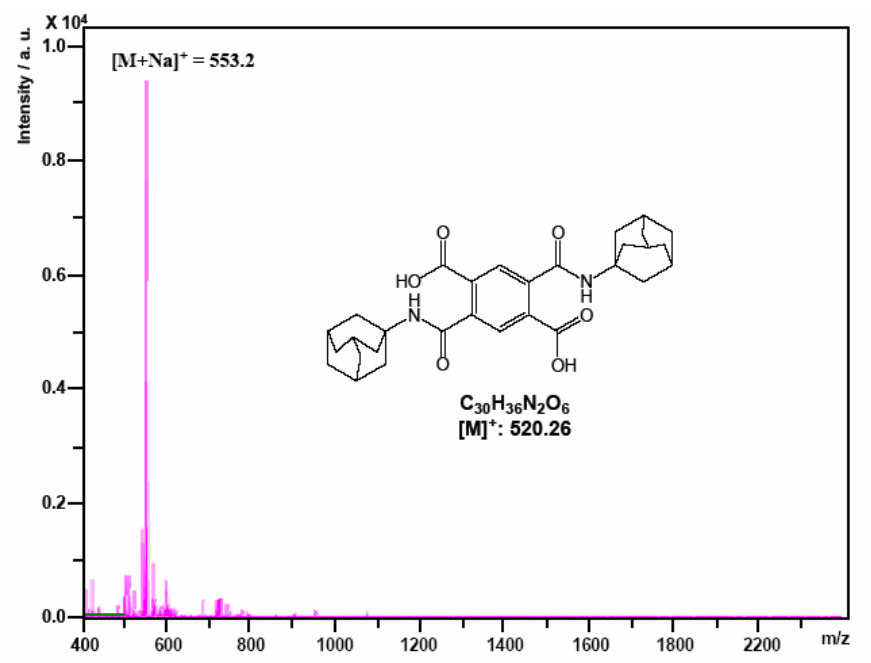

Figure 3.- MALDI-TOF of $\mathrm{Ad}_{2}$.

SLS and DLS Measurements. A Brookhaven instrument constituted by a BI2030AT digital correlator with 136 channels, and a BI-200SM goniometer was used. The light source was a Uniphase solid-state laser system model 4601 operating at 532 $\mathrm{nm}$. The refractive index measurements were performed by an ATAGO differential refractometer model DD7. A description of the experiments and theory has been recently provided. ${ }^{23}$ In the SLS measurements, the $q \rightarrow 0$ limit of the excess Rayleigh ratio $\Delta R_{\theta}$ values $\left(\Delta \mathrm{R}_{0}\right)$ was analyzed by means of the equation

$$
\frac{c K}{\Delta R_{0}}=\frac{1}{M_{a p p}}
$$

where $c, M$, and $M_{\text {app }}$ are the solute concentration $\left(\mathrm{g} \mathrm{mL}^{-1}\right)$, the molecular weight, and the apparent molecular weight, respectively, and $K$ is a constant that depends on the solvent refractive index, the solution refractive index increment $\left(0.156 \mathrm{~mL} \cdot \mathrm{g}^{-1}\right)$, and the laser wavelength. The measurements were performed in the range $30-150^{\circ}$ of the scattering angle. A linear extrapolation as a function of $q^{2}$ was performed whenever an angular dependence was observed. Otherwise, the $\Delta R_{90^{\circ}}$ was used. To prevent mold growing, these experiments were carried out in the presence of sodium azide $(10 \mathrm{mg}$ $\left.\mathrm{mL}^{-1}\right)$.

\section{Results and discussion}

TEM images and light scattering measurements demonstrate that $\mathrm{Ad}_{2}$ molecules self-assemble into big fibrillar aggregates (width value $19 \pm 7 \mathrm{~nm}$ ) (Figure 4). This is in agreement with a previous report in which another adamantyl dimer was described as a 
powerful surfactant with a great tendency to self-aggregation, ${ }^{15}$. However, in spite of the crosslinking of fibrillar aggregates by intermolecular interactions, the viscosity of the $\mathrm{Ad}_{2}$ solutions do not show any significative increment of the viscosity. DLS and SLS measurements (Figure 5 and 6 ) also evidence that the size of aggregates increases with time.

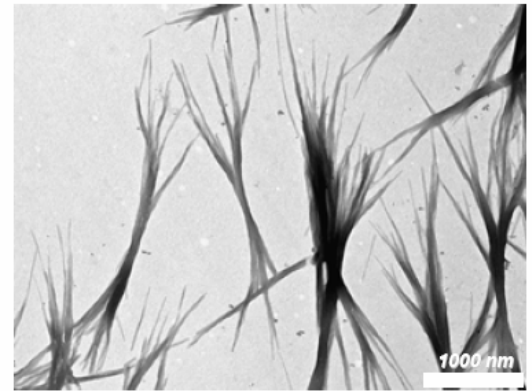

(a)

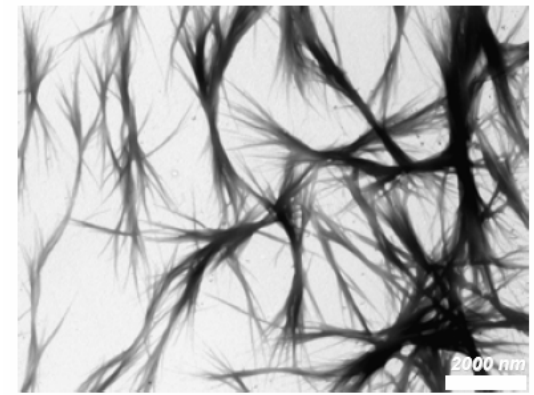

(b)

Figura 4.- TEM images of (a) $\left[\mathrm{Ad}_{2}\right]=4.1 \mathrm{mM}$ and, (b) $\left[\mathrm{Ad}_{2}\right]=8.0 \mathrm{mM}$ in $50 \mathrm{mM}$ of sodium azide in $\mathrm{H}_{2} \mathrm{O}$.

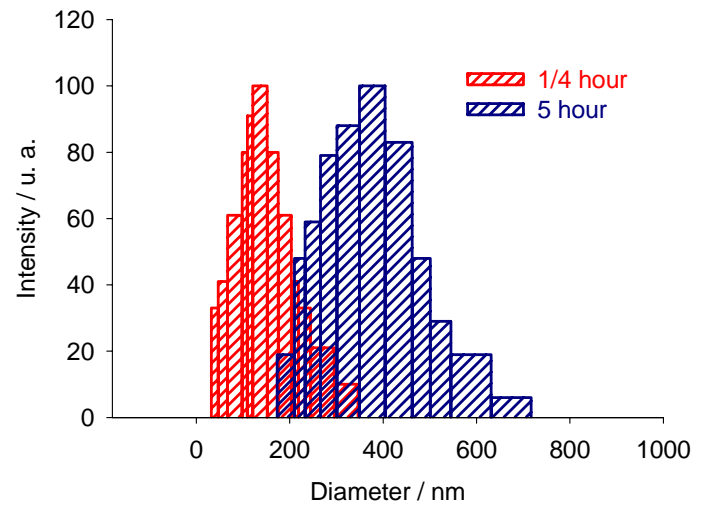

Figure 5.- $\mathrm{CONTIN}$ analysis $\mathrm{Ad}_{2} 11.2 \mathrm{mM}$ in $\mathrm{NaN}_{3} 150 \mathrm{mM}$ at $\mathrm{T}=25,0 \pm 0,2^{\circ} \mathrm{C}$.

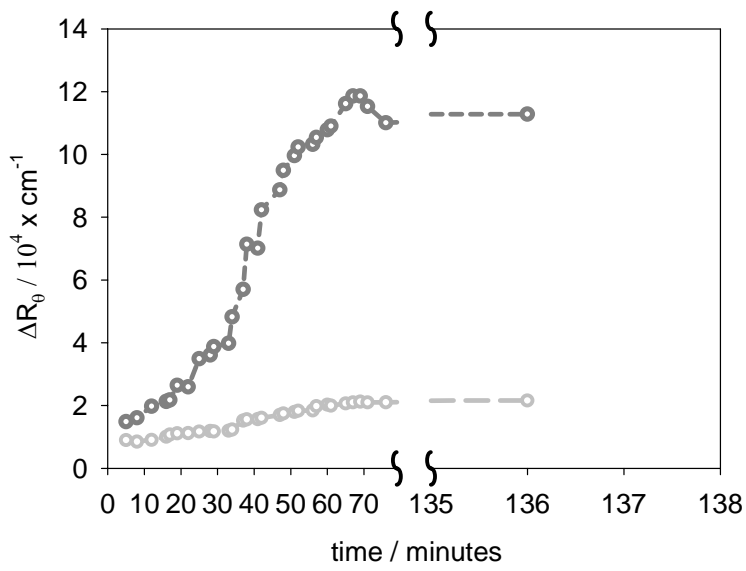

Figure 6.- SLS kinetic study of $\mathrm{Ad}_{2}$ aggregation process in sodium azide $150 \mathrm{mM}$ at $\mathrm{T}=25,0 \pm 0,2$ ${ }^{\circ} \mathrm{C}$. [Ad2] $=11.2 \mathrm{mM}$. (-०-) $\theta=90^{\circ}$ y (-o-) $\theta=40^{\circ}$. 
When $\beta \mathrm{CD}$ is added to a solution of $\mathrm{Ad}_{2}$, the big aggregates are fully disrupted as results in Table 1 show. It is to say, light scattering measurements reveal that adamantyl complexation by cyclodextrin avoid $\mathrm{Ad}_{2}$ aggregation. For checking the validity of the experimental measurements, the molecular weight and the hydrodynamic diameter of $\beta C D_{2} E D T A$ were also measured. The obtained values $\left(M_{\mathrm{w}}=2.3 \times 10^{3} \mathrm{~g}\right.$ $\mathrm{mol}^{-1}$ and $\left.1.3 \pm 0.6 \mathrm{~nm}\right)$ are in good agreement with the molecular weight deduced from its formula $\left(2.5 \times 10^{3} \mathrm{~g} \mathrm{~mol}^{-1}\right)$ and the molecular size of $\beta C D_{2} E D T A$ (the height of one cyclodextrin cone is around $0.8 \AA)^{24}$

Tabla 1.- Light Scattering measurements of $\mathrm{Ad}_{2}$ and $\beta \mathrm{CD}$ mixutres at $25,0 \pm 0,2{ }^{\circ} \mathrm{C}$ and 10 $\mathrm{mg} \cdot \mathrm{mL}^{-1}$ of sodium azide. $\mathrm{PM}_{\mathrm{Ad} 2}=564,58 \mathrm{~g} \cdot \mathrm{mol}^{-1} \cdot \mathrm{PM}_{\beta C D}=1135 \mathrm{~g} \cdot \mathrm{mol}^{-1}$

\begin{tabular}{|c|c|c|c|c|c|c|}
\hline \multicolumn{2}{|c|}{ Ratio } & \multicolumn{2}{c|}{ Concentration/10 } \\
\hline $\mathrm{Ad}_{2}$ & $\beta \mathrm{CD}$ & {$\left[\mathrm{Ad}_{2}\right]$} & {$[\beta \mathrm{CD}]$} & $\boldsymbol{R}_{\boldsymbol{h}} / \mathbf{n m}$ & $\boldsymbol{M}_{a p} / \mathbf{1 0}^{\mathbf{3}} \boldsymbol{g} \cdot \mathbf{m o t} \boldsymbol{I}^{\boldsymbol{I}}$ & $\boldsymbol{n}_{a g}$ \\
\hline 1 & 1 & 11.8 & 12.3 & $1.3 \pm 0.4$ & $2.0 \pm 0.4$ & $1.1 \pm 0.3$ \\
\hline 1 & 2 & 6.6 & 14.0 & $1.4 \pm 0.4$ & $2.9 \pm 0.3$ & $1.0 \pm 0.1$ \\
\hline 1 & 2 & 27.5 & 55.3 & $1.3 \pm 0.3$ & $2.7 \pm 0.3$ & $0.96 \pm 0.12$ \\
\hline
\end{tabular}

Table 2 shows the experimental results for aqueous solutions with identical concentrations of $\mathrm{Ad} 2$ and $\beta C D_{2} E D T$. Even though we neglected the interparticle interaction, the results very clearly indicate the formation of a $\mathrm{Ad}_{2}: \beta C D_{2} E D T A$ polymer with a polymerization degree of about 5 (i. e., 5 monomer of each interacting species). This value does not show any concentration dependence, in agreement with data reported for polymers with similar flexibility. ${ }^{16}$ Furthermore, a good correlation between the hydrodynamic radius and the molecular weight is observed.

Table 2.- Light Scattering measurements of $\mathrm{Ad}_{2}$ and $\beta C D_{2} E D T A$ mixtures at $25,0 \pm 0,2{ }^{\circ} \mathrm{C}$ and $10 \mathrm{mg} \cdot \mathrm{mL}^{-1}$ of sodium azide. ${ }^{\#}$ Concentration of each reactant. $\mathrm{PM}_{\beta C D 2 E D T A}=2518,17 \cdot \mathrm{g} \cdot \mathrm{mol}^{-1}$, $\mathrm{PM}_{\mathrm{Ad} 2}=564,58 \mathrm{~g} \cdot \mathrm{mol}^{-1}$.

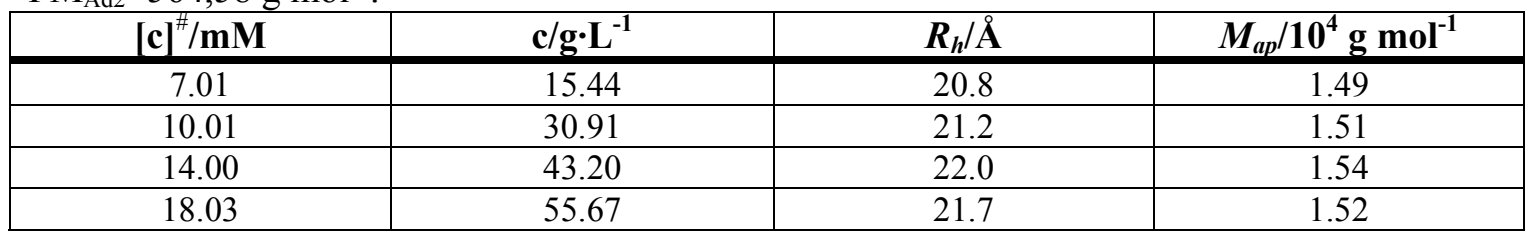

The average degree of polymerization, $D P$, in supramolecular polymers is dependent on the concentration of the solution and the association constant. ${ }^{8,18}$ Equation 2 shows that polymers with a high molecular weight can only be obtained when the association constant is high. 
$D P=\frac{1}{(1-p)}=2 K[H]_{0} /\left\{\left(1+4 K[H]_{0}\right)^{1 / 2}-1\right\}$

By using a value of $K=6,1 \times 10^{5} \mathrm{M}^{-1}$ for the $\mathrm{Ad}_{2} / \beta C D_{2} E D T A$ interaction, ${ }^{21}$ and the host concentration $[H]_{0}$, Equation 2 is simplified to Equation 3

$$
D P=\left(K[H]_{0}\right)^{1 / 2}
$$

From this equation, values of $D P$ in the interval 65-105 should be expected. Thus, it seems that SLS data do not adequately represent the actual degree of polymerization. This is in agreement with SAXS measurements and Monte Carlo simulations performed by Galantini et $a l^{23}$ and their proposition of a shrunk conformation of the polymer in aqueous solution without the formation of stable cyclic structures, as proposed for other oligomers. $^{25}$

\section{Conclusions}

The formation of polymer-like entities by adamantane and $\beta$-cyclodextrin dimers in aqueous solution was demonstrated by detailed light scattering experiments. $\mathrm{Ad}_{2}$ selfaggregates in aqueous solution but the addition of $\beta$-cyclodextrin prevents the formation of such aggregates.

Acknowledgment. The authors from USC thank the Ministerio de Ciencia y Tecnología (Project MAT2004-04606) and Xunta de Galicia (PGIDIT05PXIC26201PN) for financial support.

\section{Bibliography}

1. Ciferri, A. Macromol. Rapid Commun. 2002, 23(9), 511-529.

2. Gohy, J.-F.; Lohmeijer, B. G. G.; Schubert, U. S. Chem. Eur. J. 2003, 9(15), 3472-9.

3. Russell, T. P.; Jerome, R.; Charlier, P.; Foucart, M. Macromolecules 1988, 21(6), 1709-17.

4. Sivakova, S.; Wu, J.; Campo, C. J.; Mather, P. T.; Rowan, S. J. Chem. Eur. J. 2006, 12(2), 44656.

5. Kitagishi, H.; Oohora, K.; Yamaguchi, H.; Sato, H.; Matsuo, T.; Harada, A.; Hayashi, T. J. Am. Chem. Soc. 2007, 129(34), 10326-7.

6. Scherman, O. A.; Ligthart, G. B. W. L.; Ohkawa, H.; Sijbesma, R. P.; Meijer, E. W. PNAS 2006, 103(32), 11850-5.

7. Park, T.; Zimmerman, S. C. J. Am. Chem. Soc. 2006, 128(43), 13986-7.

8. Huang, F.; Nagvekar, D. S.; Zhou, X.; Gibson, H. W. Macromolecules 2007, 40(10), 3561-7.

9. Alvarez Parrilla, E.; Ramos Cabrer, P.; Singh, A. P.; Al-Soufi, W.; Meijide, F.; Rodríguez Núñez, E.; Vázquez Tato, J. Supramol. Chem. 2002, 14(5), 397-404. 
10. Alvarez Parrilla, E.; Ramos Cabrer, P.; Al-Soufi, W.; Meijide, F.; Rodríguez Núñez, E.; Vázquez Tato, J. Angew. Chem. Int., Ed. 2000, 39(16), 2856-2858.

11. Ramos Cabrer, P.; Alvarez-Parrilla, E.; Meijide, F.; Seijas, J. A.; Rodríguez Núñez, E.; Vázquez Tato, J. Langmuir 1999, 15(17), 5489-5495.

12. Liu, Y.; Wang, H.; Liang, P.; Zhang, H.-Y. Angew. Chem. Int. Ed. 2004, 43(20), 2690-4.

13. Brunsveld, L.; Folmer, B. J. B.; Meijer, E. W.; Sijbesma, R. P. Chem. Rev. 2001, 101(12), 407197.

14. Soto Tellini, V. H.; Jover, A.; Galantini, L.; Meijide, F.; Vázquez Tato, J. Acta Crystal. 2004, B60(2), 204-210.

15. Soto Tellini, V. H.; Jover, A.; Carrazana Garcia, J.; Galantini, L.; Meijide, F.; Vázquez Tato, J. J. Am. Chem. Soc. 2006, 128, 5728-5734.

16. Hasegawa, Y. ; Miyauchi, M.; Takashima, Y.; Yamaguchi, H.; Harada, A. Macromolecules 2005, 38(9), 3724-30.

17. Deng Wei; Yamaguchi Hiroyasu; Takashima Yoshinori; Harada Akira Angew. Chem. Int. Ed. 2007, 46(27), 5144-7.

18. A. Ciferri, ed. Supramolecular Polymers, 2nd Edition; Taylor $\neg$ Francis: New York, 2005.

19. Breslow, R.; Belvedere, S.; Gershell, L.; Leung, D. Pure Appl. Chem. 2000, 72(3), 333-342.

20. Ohga, K.; Takashima, Y.; Takahashi, H.; Kawaguchi, Y.; Yamaguchi, H.; Harada, A. Macromolecules 2005, 38(14), 5897-5904.

21. Carrazana, J.; Jover, A.; Meijide, F.; Soto, V. H.; Vázquez Tato, J. J. Phys. Chem. 2005, 109 (19), 9719-26.

22. Galantini, L.; Jover, A.; Leggio, C.; Meijide, F.; Pavel, N. V.; Soto Tellini, V. H.; Vázquez Tato, J.; Tortolini, C. J. Phys. Chem. B 2008, 112(29), 8536-41.

23. Leggio, C.; Anselmi, M.; Di Nola, A.; Galantini, L.; Jover, A.; Meijide, F.; Pavel, N. V.; Soto Tellini, V. H.; Tato, J. V. Macromolecules 2007, 40(16), 5899-5906.

24. Saenger, W.; Jacob, J.; Gessler, K.; Steiner, T.; Hoffmann, D.; Sanbe, H.; Koizumi, K.; Smith, S. M.; Takaha, T. Chem. Rev. 1998, 98, 1787-1802.

25. Ohga, K.; Takashima, Y.; Takahashi, H.; Miyauchi, M.; Kawaguchi, Y.; Yamaguchi, H.; Harada, A. Chem. Lett. 2005, 34(3), 320-1. 